\title{
Los conciertos recaudatorios en la Hacienda municipal
}

1.-La recaudación de los recursos de las Entidades locales, dice el artículo 277 del Decreto de 25 de enero de 1946, podrá realizarse directamente, por arriendo, por concierto o por gestión afianzada.

Es indudable que las Haciendas públicas deben procurar recaudar directamente, con órganos propios, sin dejar en manos del particular, guiado por móviles de lucro, función tan específica de derecho público como es la de obtener los recursos con que hacer frente a sus necesidades en orden a cumplir los fines de interés general que les están atribuídos. Por ello, el arrendamiento no debe utilizarse y el hacerlo significa generalmente una demostración de incapacidad por parte de la Administración para realizar en condiciones adecuadas la función recaudatoria.

El concierto no es tampoco un procedimiento que deba usarse con carácter general, pues muy a menudo puede significar una reducción en las cuotas que conforme a los principios fiscales debieran satisfacerse por los contribuyentes. Pero no se puede por menos de reconocer que en algunos tributos la investigación es tan difícil, la determinación de cuotas tan expuesta a errores por carecer de suficientes elementos para precisar la base tributaria, tan poco económico el trabajo de inspección y tan molesto para el contribuyente que es preciso acudir al procedimiento de concierto, merced al cual el contribuyente se obliga a satisfacer a la respectiva Hacienda pública una cuota alzada 
de antemano fijada por mutuo acuerdo entre ambos para un período de imposición determinado.

2.-El legislador no ha querido dejar libertad absoluta a los entes locales territoriales para aplicar este procedimiento recaudatorio. Sin duda recelando un uso indebido del mismo, ha querido restringir su aplicación a los casos por el mismo legislador determinados. $\mathrm{Y}$ así ha establecido en el artículo 282 que la recaudación de exacciones municipales o provinciales podrá realizarse por el sistema de conciertos con los gremios u organismos en que se agrupen los industriales, en los casos no prohibidos en este Decreto. Y aunque no existe una concordancia acabada con el_268- $d$ ), el cual establece "que salvo lo especialmente dispuesto en este Decreto en materia de conciertos, aportaciones o auxilios, será nulo todo pacto, contrato o sistema que acuerden las Corporaciones locales y que tengan por objeito la obligación de contribuir, la forma o la cuantía de las exacciones", pues mientras en el primero se otorga una libertad para el concierto en los casos no prohibidos, en el segundo se prohibe concertar, excepto en los casos previamente determinados por el Decreto, juzgamos más congruente el precepto del artículo 268 con el desarrollo de las disposiciones contenidas en el Decreto de 25 de enero de 1946 , que el del 282 , por cuanto no existen (in concreto" casos en los que se prohiba el concierto, y sí solo el precepto general del artículo 268 que declara nulos todos los expresamente no permitidos por el legislador. Ahora bien, ¿cuáles son los permitidos? ¿En qué casos el legislador ha dispuesto que puede concertarse una determinada exacción?

No hay más remedio que acudir al Decreto y compulsar sus disposiciones para extraer los casos todos en que tal facultad de concierto se consigne expresamente. De este modo, sin miedo a equivocaciones, podremos saber cuándo se permite y cuándo no el concierto. Estos casos son los siguientes:

1.-Contribucionés especiales. El Ayuntamiento podrá concertar con las personas sujetas a la obligación de contribuir especialmente la ejecución directa por los interesados de una parte de la obra o instalación en equivalencia de las cuotas que les corresponda satisfacer o de una parte de ellas; pero en nin- 
gún caso el importe total de la obligación podrá ser menor del que corresponda según ley. No se podrá concertar la ejecución total de la obra o instalación sino cuando el coste se satisfaga integramente por los interesados. (Art. $32,1 .^{\circ}$ y $2 .^{\circ}$ del Decreto de 25 de enero de 1946).

2.-Arbitrio con fin no fiscal sobre consumiciones en cafés, bares, etc. Podrá exaccionarse por concierto gremial, pero ajustado a lo dispuesto en el artículo 282 del Decreto. (Art. 51, $4 .^{\circ}$ ).

3.-Contribución de usos y consumos. Tarifa 5.", cedida por el Estado. Se permite el concierto con los gremios que se encargan de recaudar de los obligados al pago, debiendo aquéllos. ingresar el importe del concierto en la forma y plazo que se establezca al efecto. (Art. 56-b) y $57,1 .^{\circ}$ ).

4.-Arbitrios sobre el consumo de bebidas espirituosas y alcoholes, carnes, volatería y caza menor, y pescados y mariscos finos. Se permite el concierto con los gremios correspondientes. siempre que se cumplan los siguientes requisitos:

a) Que el núcleo mayor de población del Municipio tenga más de 5.000 habitantes de hecho, o que, aun sin reunir tal requisito, se produzca en el término municipal dos tercios por lo menos del propio consumo de la especie gravada.

b) Que se ajuste la tramitación a lo dispuesto en el artículo 282 .

El concierto puede abarcar todas las especies sujetas al arbitrio o sólo alguna o algunas de ellas. (Art. 127).

En las llamadas zonas.libres, que comprende la población diseminada y los pequeños núcleos de población que no pueden prácticamente soportar los gastos de fiscalización, se hará efectivo el arbitrio mediante conciertos particulares obligatorios con los productores, expendedores y consumidores. Pero si en dichas zonas hubiere expendedores de la especie concertados, en tal caso deja de ser obligatorio para los consumidores de estas zonas libres. (Art. 128-1. ${ }^{\circ}$ y $2 .^{\circ}$ ).

5.-Arbitrio sobre traviesas en espectáculos públicos. La recaudación, dice el artículo $147-5 .^{\circ}$ de este arbitrio, podrá efectuarse mediante concierto con las empresas, directamente de los que hagan las apuestas o valiéndose de agentes corredo- 
res, sean propios o dependientes de las empresas, con la facultad de obligar a éstas a que recauden el arbitrio gratuitamente y sin perjuicio de la fiscalización que en todo caso pueda ejercer el Ayuntamiento.

Otros casos hay en los que no se puede hablar propiamente de concierto, como por ejemplo la recaudación del arbitrio sobre pompas fúnebres que puede encomendarse a las empresas dedicadas a este negocio, las que harán efectivo el importe del arbitrio municipal al cobrar el servicio por ellas prestado (art. 146-4..$^{\circ}$, pues en realidad se trata de una subrogación en la función recaudatoria que, correspondiendo normalmente a la Administración municipal, puede ésta legalmente descargar en las empresas de pompas fúnebres, las que habrán de entregar el importe de lo recaudado a la Administración municipal, sin previo concierto alguno respecto de la cantidad a recaudar. Tampoco puede catalogarse como concierto la participación del Ayuntamiento en los ingresos brutos o productos netos de los concesionarios de servicios de abastecimientos de aguas, tranvías urbanos, gas y electricidad, teléfonos urbanos y otros (art. 14-1. $)$ en concepto de derechos y tasas por aprovechamientos especiales.

Existe también una particular manifestación de esta forma de concierto que no se da entre Administración municipal y contribuyente, sino entre el Ayuntamiento y las Entidades locales menores, pudiendo éstas concertar con el Ayuntamiento el pago de uno o varios cupos alzados de todas las exacciones exigibles a sus habitantes, subrogándose en su lugar en las facultades relativas a organización de la Hacienda, establecimiento y recaudación de imposiciones municipales (art. 2-5..$^{\circ}$ ), facultad esta que presenta interesantísimos aspectos de orden doctrinal y práctico, cuyo estudio escapa al objeto perseguido en estas líneas.

3.-Forma de los conciertos. ¿Es libre la Administración para llegar al concierto sin traba alguna de forma, o por el contrario habrá de sujetarse a normas legales su actuación? Según hemos ya dicho, no se podrá acudir al concierto más que en los casos en que el legislador lo permita, de tal modo que se de- 
clara nulo de pleno derecho todo otro pacto, contrato o sistema en relación con la obligación de contribuir, con la cuantía de la exacción o con la forma de practicarla. De manera que cuando el legislador determina la forma en que ha de realizarse habrá de ajustarse el concierto a la misma. Si se establece que se ha de hacer según las prevenciones del art. 282, conforme a sus disposiciones será preciso formalizar el concierto. Si no impone determinada forma, el concierto habrá de celebrarse, por regla general, según las normas contenidas en el art. 282, que pueden sintetizarse en éstas:

a) Instancia del gremio, organismo o particular interesado pidiendo el concierto. Se unirá certificación del acuerdo en tal sentido, si el peticionario es una persona colectiva.

b) Estudio y propuesta, en su caso, por la Corporación de las condiciones en que habría de llegarse al concierto. Tal propuesta contendrá al menos:

$\left.a^{\prime}\right)$ La cifra líquida del concierto. Para fijarla servirá de base la recaudación del año anterior, como mínimo, sin que pueda sufrir disminución alguna por premios de cobranza, partidas fallidas ni otro cualquier concepto, no obstante lo cual se podrá variar en el caso de sufrir variación, durante el concierto, los tipos impositivos o los precios sobre los que gire el concierto, practicándose las rectificaciones en más o en menos, excepto en el caso de que supongan un 10 por 100 o menos de las cifras primitivaś, pues entonces no se alterará la cifra concertada.

$\left.b^{\prime}\right)$ Los plazos de ingreso. Se hará efectivo el concierto por dozavas partes, anticipadamente; es decir que la dozava parte del importe anual se ingresará al principio del mes a que corresponda; la falta de ingreso es causa suficiente para rescindir el concierto.

$\left.c^{\prime}\right)$ Su duración, que será al menos de dos años, prorrogables de año en año por la tácita, si no se avisa su revisión o rescisión por cualquiera de las partes con un trimestre de antelación a su vencimiento.

$\left.d^{\prime}\right)$ Garantías de su cumplimiento. A estos efectos se deberá depositar por la persona individual o colectiva (aunque la 
disposición sólo habla de gremio) a disposición del Presidente de la Corporación, y estimamos que será conveniente establecer que el depósito se hará en la Caja de la Administración que concierte, el importe de un mes. Se debe hacer constar el derecho de la Corporación a inspeccionar las oficinas y recabar cuantos datos y elementos de comprobación estime convenientes y se relacionen con la exacción concertada.

$\left.e^{\prime}\right)$ Las sanciones que se han de imponer, llegado el caso.

$\left.f^{f}\right)$ Las causas que den lugar a la rescisión.

c) Una vez que se acepten por el peticionario del concierto las condiciones fijadas por la Administración se formalizará el oportuno contrato para el que no es preciso, según nuestra opinión, otorgar escritura pública, sino que es bastante el documento privado, o mejor, el documento público administrativo que se otorga en presencia del Secretario de la Administración pública local y el cual da fe de lo que en él se contiene. De cualquier modo, parece un poco inadecuada la terminología, pues si el procedimiento recaudatorio es de derecho público y se impone "velis nolis" frente al obligado, no parece cambie su naturaleza jurídica porque al particular se le permita discutir con la Administración la cuantía, la forma, etc., de su obligación. Una vez fijados los términos, la exacción se rige por normas de derecho público, y la Administración procede unilateralmente en el cumplimiento del mismo. Sería, pues, más administrativo que la Administración, una vez obtenida la conformidad del presunto concertado a su propuesta, acordase que la recaudación de aquel tributo se realizase conforme a dichas normas, y así lo notificase al interesado para que las obligaciones de derechos recíprocos quedasen establecidas.

N. Rodríguez Moro. 